\title{
A METHOD FOR PREPARING SINGLE MAMMALIAN OVA FOR CYTOLOGICAL STUDIES USING LIGHT AND ELECTRON MICROSCOPY
}

\author{
P. L. SENGER AND R. G. SAAGKE \\ Department of Dairy Science, Virginia Polytechnic Institute, Blacksburg, Virginia 24061
}

(Received 21st fuly 1969)

The inability to define accurately the cytological characteristics associated with fertile mammalian ova is due, at least in part, to difficulty in obtaining and preparing adequate numbers of these cells for critical morphological studies. This communication describes a method which has proved useful in preparing single bovine ova for study using both light and electron microscopy.

Bovine ova were recovered by follicular aspiration immediately following slaughter. Aspiration was accomplished with a 20-gauge hypodermic needle and a 2-ml syringe (Pl. 1, Fig. 1). The follicular fluid was placed in a watch-glass (Pl. 1, Fig. 2) and scanned, using a stereomicroscope in order to locate the ovum. Following location, the ovum was transferred with a micro-pipette from the follicular fluid to a fixation ampoule suspended in an ice water bath (Pl. 1, Fig. 3). The fixation ampoules were prepared from 6- to 9- in. disposable Pasteur pipettes which had been scored and broken in order to shorten the narrow portion. The narrow tip of the pipette was sealed by flaming. This design (Pl. 1, Fig. 4) restricted the ovum to a small volume of fixative after it settled into the narrow tip of the fixation ampoule. The settling facilitated the location of the ovum after the fixation period. In addition, the ampoule could be suspended easily in an ice water bath for fixation at $0^{\circ} \mathrm{C}$ (Pl. 1, Fig. 3). The ova were fixed in $1 \%$ osmium tetroxide buffered to $\mathrm{pH} 7.4$ with veronal-acetate (Palade, 1952) or in 3\% glutaraldehyde buffered to $\mathrm{pH} 7.4$ with 0.1 M-phosphate. Fixation times ranged from $30 \mathrm{~min}$ to $1 \mathrm{hr}$. Ova fixed in glutaraldehyde were washed in the phosphate buffer overnight and subsequently placed in 0.1 m-phosphate buffered osmium tetroxide for $1 \mathrm{hr}$. Caution should be exercised in choosing fixatives. The preservation of cytological detail is known to vary with the tissue as well as with the fixatives used. Modifications of fixatives and buffers may be necessary if ova of different developmental stages in the bovine or ova from other species are to be studied.

Following fixation, the tip of the ampoule was scored with a diamond stylus (Pl. 1, Fig. 5) and broken. The ovum was removed from the tip of the ampoule and subsequently dehydrated in Syracuse watch-glasses (Pl. I, Fig. 6) using a graded series of ethanol $(80,95,100 \%)$. Subsequently, embryological watchglasses (A. H. Thomas, Philadelphia, Cat. No. 9844) have been found to be superior due to their smaller size and spherical concavity. A dehydration period 
of approximately $5 \mathrm{~min}$ was allowed in each alcohol bath. Following dehydration, ova were transferred to a $1: 1$ mixture of propylene oxide and Epon 812 for approximately $5 \mathrm{~min}$. The use of propylene oxide alone as a vehicle to enhance penetration of Epon 812 was avoided because of the violent movement of the ova in this highly volatile material. Ova were transferred directly from the Epon-propylene oxide mixture to Epon 812 resin for embedding.

Embedding was accomplished using a two-step process. Initially, three drops of Epon 812 were placed in a No. 3 Beem capsule (Ernest F. Fullam, Inc., P.O. Box 444, Schenectady, N.Y., Cat. No. 5206). The small quantity of Epon facilitated exact positioning of the ovum in the tip of the Beem capsule with the aid of a dissecting needle and a stereomicroscope. The initial three drops containing the ovum were polymerized for $6 \mathrm{hr}$ at $60^{\circ} \mathrm{G}$ in a drying-oven. The initial hardening of the Epon 812 prevented possible movement of the ovum when the capsules were subsequently filled. The filled capsules were allowed to polymerize for an additional 12 to $14 \mathrm{hr}$ at $60^{\circ} \mathrm{C}$. Therefore, total polymerization time for the resin surrounding the ovum was 18 to $20 \mathrm{hr}$.

Following embedding and polymerization, the ova were sectioned on a Porter-Blum MT-2 ultramicrotome. Thick sections ranging from 0.5 to $1 \mu$ were cut and subsequently stained with Azure II according to the method of Joen (1965). These sections provide more cytological information than can be obtained from whole mounts using phase contrast or bright-field microscopy. Thin sections (600 to $1500 \AA$ ) were also cut for study using the electron microscope.

The difficulties in manipulating single ova during fixation, dehydration, and embedding have been minimized with this procedure. Initial efforts to prepare ova for electron microscopy have resulted in successful embedding of approximately $90 \%$ of all ova recovered.

Gratitude is expressed to Dr C. W. Heald for photographic assistance in the preparation of Plate 1.

\section{REFERENCES}

JoEN, K. W. (1965) Simple method for staining and preserving epoxy resin-embedded animal tissue sections for light microscopy. Life Sci. 4, 1839.

Palade, G. E. (1952) A study of fixation for electron microscopy. F. $\exp$. Med. 95, 285. 

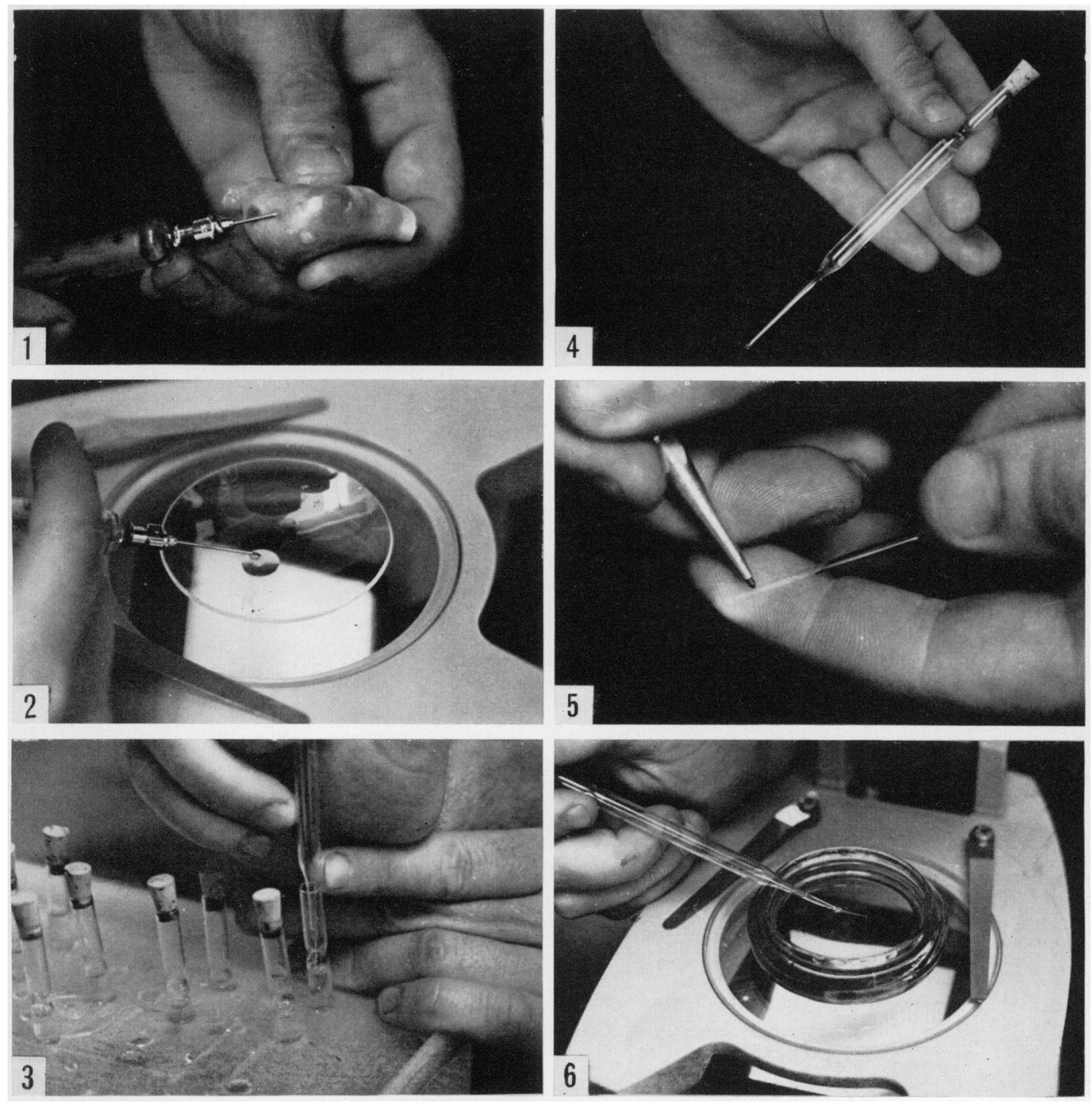

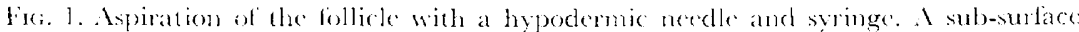
approach through the owarian contex was used to prevent lows of follicular fluid.

Eir. 2. Thansfer of follicular fluid to a match-glass.

Ife. 3. 1)eposit of ahe oxum inte the fixation ampoule suspencied in an ier water bath.

Fie. t. Fixation anpente containing the fixative.

lis. 5. Scoring the ampoule with a stylus.

lis. 6. Dehyclation in a Syracuse watch-glass. 